\title{
Racial Disparities in Thyroid Disease Care
}

\section{Colleen Gavigan and David S. Cooper}

\author{
Division of Endocrinology, Diabetes, and Metabolism; The Johns Hopkins University School of Medicine; \\ Baltimore, Maryland, U.S.A.
}

Review of: Maduka RC, Gibson CE, Chiu AS, Raymond AJ, Wills-Johnson N, Azar SA, Oliveira K, Ahuja V 2020 Racial disparities in surgical outcomes for benign thyroid disease. Am J Surg. Epub 2020 Jul 6. PMID: 32669203.

\section{SUMMARY}

\section{Background}

Recent protests over police brutality as well as the COVID-19 pandemic have brought to light the systemic racism that pervades all sectors of our society, including the practice of medicine $(1,2)$. Not unexpectedly, racial inequity is found in many areas of endocrinology (3), most notably in diabetes. A PubMed search, completed on October 2, 2020, of "racial disparities in diabetes" found over 1000 papers on this subject published since 2015.

Disparities in the care of patients with thyroid disease have also been reported, including increased risks of surgical complications in minorities with malignant thyroid disease $(4,5)$. In the current study, Maduka et al. sought to examine the issue of racial inequity in patients with benign thyroid disease (6). Given the frequent use of surgery to manage benign thyroid conditions, including multinodular goiter, benign nontoxic or toxic adenoma, and Graves' disease, this is an important concern.

\section{Methods}

This is a retrospective review of data from the American College of Surgeons National Surgical Quality Improvement Program (NSQIP). The study population consisted of all adults $>17$ years old who underwent total or partial thyroidectomy for nonmalignant disease, including Graves' disease, goiter, adenoma, or "other benign nodule," from
2016 to 2017 in the United States, captured within a multi-institutional database. Demographic and other data that were recorded included race (White, Black, Hispanic, Asian, and other/unknown), sex, age group, body-mass index (BMI), previous neck surgery, and surgical indication.

Outcomes included neck hematoma; injury to the recurrent laryngeal nerve (RLN), defined as hoarseness or vocal-cord dysfunction up to 30 days after surgery; symptomatic hypocalcemia requiring medical evaluation or intravenous calcium up to 30 days after surgery; and other general surgical complications. Logistic-regression models were used to evaluate the association between outcomes and race. A multivariate model controlled for baseline data as well as the presence of end-stage renal disease while a patient was on dialysis, American Society of Anesthesiologists (ASA) class (used to classify physical status and preoperative comorbidities), and type of operation. Race was a covariate associated independently with each of the complications, and odds ratios with $95 \%$ confidence intervals were determined with White race as the reference.

\section{Results}

There were 6187 patients included, the majority of whom were female (81.3\%), non-Hispanic White (55\%), 40 to 65 years of age (56.5\%), and obese 
(48\%) with no history of neck surgery $(92.4 \%)$ and who had presented with goiter (65\%). The overall rates of postoperative complications were low, with the most common being RLN injury in 357 patients (5.2\%), followed by significant hypocalcemia in 336 (4.9\%), neck hematoma in 135 (2\%), and postoperative complications not specific to thyroid surgery in 128 (1.9\%).

Black patients had the highest incidence of neck hematoma $(3.1 \%$ vs. $1.3 \%$ in White patients, $\mathrm{P}<0.01)$, RLN injury (8.7\% vs. $4.3 \%, \mathrm{P}<0.01)$, and other surgical complications $(2.5 \%$ vs. $1.4 \%$, $\mathrm{P}<0.01)$. The incidence of hypocalcemia was highest in Hispanic patients (7.3\%), but this was not statistically significantly different when compared with other ethnicities.
When baseline and clinical factors were controlled for, the odds of each of the following outcomes in Black patients were significantly greater than in White patients: neck hematoma (OR, 2.46; $95 \% \mathrm{Cl}, 1.61-$ 3.77), RLN injury (OR, 1.93; 95\% $\mathrm{Cl}, 1.50-2.49)$, and surgical complications (OR, 1.82; 95\% Cl, 1.17-2.83).

\section{Conclusions}

When demographics and clinical factors including comorbidities and surgical risk are considered, Blacks who undergo surgery for benign thyroid disease have a higher incidence of neck hematoma, RLN injury, and other general complications than do Whites. In addition, relative to Whites, Asians have a higher risk of RLN injury, and Hispanics have a nonstatistically significant increase in postoperative hypocalcemia.

\section{COMMENTARY}

Racial disparities have long been described in medicine in general (1) and in endocrinology in particular (3). There have been several studies on the subject in the area of thyroid disease (Table 1). The data of Maduka et al. (6) are consistent with prior studies that included thyroidectomy for malignant disease, showing that Black patients have worse outcomes $(4,5,15)$. As discussed by Maduka et al., the causes of the observed disparities are numerous (6), including disease severity at presentation, access to care, health literacy, surgeon experience and volume of cases, and patient mistrust of the health care system. For example, in both benign and malignant thyroid conditions, minority patients appear to present with more advanced disease $(7,8,16)$. This may be a direct result of reduced access to care, as demonstrated in a study by Lim et al. (16). This report identified that public hospital patients, who were predominantly minorities and those who lacked private insurance, were more likely to present with advanced stage disease than their counterparts at an academic teaching hospital.

We should also consider whether management strategies are contributing to these disparate outcomes. For example, Elfenbein et al. found that Black patients were more likely than Whites to undergo surgical management of Graves' disease (9). I wata et al. noted that Whites were $62 \%$ more likely to undergo fine-needle aspiration (FNA) biopsy for incidentally identified thyroid nodules (13) than were non-White patients. In evaluating the management of thyroid cancer, including extent of surgery and administration of radioactive iodine (RAI) ablation, Famakinwa et al. found that White patients were more likely than Blacks to receive the recommended interventions in accordance with the American Thyroid Association clinical practice guidelines for thyroid nodules and thyroid cancer (12).

Surgical expertise and volume are also important considerations. A landmark study by Sosa et al. 


\section{THYROID SURGERY Racial Disparities in Thyroid} Disease Care

Colleen Gavigan and David S. Cooper

showed that higher surgeon volume predicts lower complication rates after thyroid surgery (17). Another study by Sosa et al. (5) revealed that the majority of Blacks had surgery by the lowest-volume surgeons, as compared with a smaller proportion of Whites. In another study, Al-Qurayshi et al. analyzed more than 20,000 thyroidectomies and found that African American patients from high-risk communities (risk was based on smoking, obesity, excessive alcohol consumption, educational level, unemployment, and income among other factors) were more commonly operated on by low-volume surgeons, with postoperative complications being more common in this population (15). However, even when surgeon volume was adjusted for, Sosa et al. found that significant racial disparities in length of stay and cost persisted (5).

In addition to a higher rate of adverse surgical outcomes among minorities, the medical management of a nonsurgical thyroid disease such as hypothyroidism appears to differ among races. For example, in hypothyroid patients older than age 65 , initiation of thyroid hormone treatment in non-White patients is significantly less likely than in White patients (10). Further, non-White patients with hypothyroidism more commonly receive generic levothyroxine rather than brand-name products (11).

\section{Table 1. Racial Disparities in Thyroid Disease Presentation, Management, and Outcomes}

\begin{tabular}{|c|c|c|}
\hline Finding & Relative Risks & Study \\
\hline \multicolumn{3}{|l|}{ Thyroid Disease at Presentation } \\
\hline More advanced disease in benign nodular disease & Blacks $>$ Whites & Kuo et al. (7) \\
\hline Later stage of thyroid cancer & Blacks $>$ Whites & Harari et al. (8) \\
\hline \multicolumn{3}{|l|}{ Thyroid Disease Management } \\
\hline Surgical treatment of Graves' disease & Blacks $>$ Whites & Elfenbein et al. (9) \\
\hline Surgery by low-volume surgeon & Blacks $>$ Whites & Sosa et al. (5) \\
\hline $\begin{array}{l}\text { Initiation of thyroid hormone administration among } \\
\text { older adults }\end{array}$ & Whites $>$ Nonwhites & Somwaru et al. (10) \\
\hline Treatment with brand-name thyroid hormone & Whites $>$ Blacks & Ross et al. (11) \\
\hline $\begin{array}{l}\text { Postoperative RAI or surgery in compliance with } \\
\text { ATA guidelines }\end{array}$ & Whites $>$ Blacks & Famakinwa et al. (12) \\
\hline FNA of incidental thyroid nodule & Whites > Blacks & Iwata et al. (13) \\
\hline \multicolumn{3}{|l|}{ Thyroid Disease Outcomes } \\
\hline Complications following thyroidectomy & Blacks $>$ Whites & $\begin{array}{l}\text { Al-Qurayshi et al. (4), Sosa et al. } \\
\text { (5), Maduka et al. (6) }\end{array}$ \\
\hline Survival rates in differentiated thyroid cancer & Whites $>$ Blacks & Harari et al. (8), Asban et al. (14) \\
\hline
\end{tabular}

Note: This is not an exhaustive compilation of all the available papers regarding racial disparities in thyroid disease. Also, in some studies, statistical significance was lost when other clinical factors were accounted for, but the above trends were still present. 
A newer concept in patient care takes into account the social circumstances and environment of the individual; these are commonly referred to as social determinants of health and can affect the presentation, management, and outcomes of illnesses. For example, Swegal et al. reported that lower household income correlated with a higher risk of disease-related death in patients with differentiated thyroid cancer (DTC) (18). Asban et al. found higher 10- and 20-year mortality rates in Black males with DTC as compared with Black females and White males and females (14). A study of Graves' disease at an urban hospital found that lower income and lack of insurance predicted whether surgical management would be chosen over medical or RAI therapy (19).

The lack of data on these social determinants of health in the NSQIP database is a limitation of the study by Maduka et al. (6). Another limitation is the lack of information on referral patterns, which, as stated above in the case of surgical experience, are likely to influence outcomes. Details on patients' medical visits leading up to surgery would also be informative. For example, referral for surgery may have been delayed because of providers' implicit biases, impaired patient-provider communication, or difficulties with patient adherence or access to care.

Investigating and addressing the causes of racial and ethnic disparities in medical and surgical care is critical to informing health care decision making. In addition to improved surgical care for racial minorities, strategies that address the barriers to high-quality care for Blacks and other minorities for all thyroid diseases are needed. Achieving health equity will require responding to social determinants of health; balancing the distribution of power, money, and resources; and improving living conditions (20). Our health care delivery systems need to be integrated with social care so that the adverse effects of social risk factors, including discrimination and lack of access to stable housing, nutritious food, reliable transportation, and education, can be mitigated (21). Hopefully, studies like the one by Maduka et al. (6) will force us to confront and challenge the status quo.

\section{Acknowledgment}

We thank Sherita Golden, MD, MHS, for her helpful suggestions in the writing of this commentary.

\section{References}

1. Smedley BD, Stith AY, Nelson AR, eds. National Academy of Sciences, Engineering, and Medicine Committee on Understanding and Eliminating Racial and Ethnic Disparities in Health Care 2003 Unequal treatment: Confronting racial and ethnic disparities in health care. Washington, DC: National Academies Press. Accessed at https://www.nap.edu/initiative/ committee-on-understanding-and-eliminating-racialand-ethnic-disparities-in-health-care

2. Hardeman RR, Murphy KA, Karbeah J, Kozhimannil KB 2018 Naming institutionalized racism in the public health literature: A systematic literature review. Public Health Rep 133:240-249.
3. Golden SH, Brown A, Cauley JA, Chin MH, GaryWebb TL, Kim C, Sosa JA, Sumner AE, Anton B 2012 Health disparities in endocrine disorders: Biological, clinical, and nonclinical factors-an Endocrine Society scientific statement. J Clin Endocrinol Metab 97(9):E1579-E1639.

4. Al-Qurayshi Z, Randolph GW, Srivastav S, Kandil E 2016 Outcomes in endocrine cancer surgery are affected by racial, economic, and healthcare system demographics. Laryngoscope 126:775-781. 
5. Sosa JA, Mehta PJ, Wang TS, Yeo HL, Roman SA 2007 Racial disparities in clinical and economic outcomes from thyroidectomy. Ann Surg 246:1083-1091.

6. Maduka RC, Gibson CE, Chiu AS, Raymond AJ, WillsJohnson N, Azar SA, Oliveira K, Ahuja V 2020 Racial disparities in surgical outcomes for benign thyroid disease. Am J Surg. Epub 2020 Jul 6.

7. Kuo LE, Simmons KD, Wachtel H, Zaheer S, Karakousis GC, Fraker DL, Kelz RR 2016 Racial disparities in initial presentation of benign thyroid disease for resection. Ann Surg Oncol 23:25712576.

8. Harari A, Li N, Yeh MW 2014 Racial and socioeconomic disparities in presentation and outcomes of well-differentiated thyroid cancer. J Clin Endocrinol Metab 99:133-141.

9. Elfenbein DM, Schneider DF, Havlena J, Chen H, Sippel RS 2015 Clinical and socioeconomic factors influence treatment decisions in Graves' disease. Ann Surg Oncol 22:1196-1199.

10. Somwaru LL, Arnold AM, Cappola AR 2011 Predictors of thyroid hormone initiation in older adults: Results from the Cardiovascular Health Study. J Gerontol A Biol Sci Med Sci 66:809-814.

11. Ross JS, Rohde S, Sangaralingham L, Brito JP, Choi L, Dutcher SK, Graham DJ, Jenkins MR, Lipska KJ, Mendoza M, et al. 2019 Generic and brand-name thyroid hormone drug use among commercially insured and Medicare beneficiaries, 2007 through 2016. J Clin Endocrinol Metab 104:2305-2314.

12. Famakinwa OM, Roman SA, Wang TS, Sosa JA 1999 ATA practice guidelines for the treatment of differentiated thyroid cancer: Were they followed in the United States? Am J Surg 199:189-198.

13. Iwata AJ, Bhan A, Lahiri S, Williams AM, Burmeister C, Chang SS, Singer MC 2018 Incidental thyroid nodules: Race/ethnicity disparities and outcomes. Endocr Pract 24:941-947.
14. Asban A, Chung SK, Xie R, Lindeman BM, Balentine CJ, Kirklin JK, Chen H 2019 Gender and racial disparities in survival after surgery among papillary and patients with follicular thyroid cancer: A 45-year experience. Clin Med Insights Endocrinol Diabetes 12:1179551419866196.

15. Al-Qurayshi Z, Randolph GW, Srivastav S, Aslam R, Friedlander P, Kandil E 2016 Outcomes in thyroid surgery are affected by racial, economic, and healthcare system demographics. Laryngoscope 126:2194-2199.

16. Lim II, Hochman T, Blumberg SN, Patel KN, Heller KS, Ogilvie JB 2012 Disparities in the initial presentation of differentiated thyroid cancer in a large public hospital and adjoining university teaching hospital. Thyroid 22:269-274.

17. Sosa JA, Bowman HM, Tielsch JM, Powe NR, Gordon TA, Udelsman R 1998 The importance of surgeon experience for clinical and economic outcomes from thyroidectomy. Ann Surg 228:320-330.

18. Swegal WC, Singer M, Peterson E, Feigelson HS, Kono SA, Snyder S, Melvin TA, Calzada G, Ghai NR, Saman DM, Chang SS 2016 Socioeconomic factors affect outcomes in well-differentiated thyroid cancer. Otolaryngol Head Neck Surg 154:440-445.

19. Jin J, Sandoval V, Lawless ME, Sehgal AR, McHenry CR 2012 Disparity in the management of Graves' disease observed at an urban county hospital: A decade-long experience. Am J Surg 204:199-202.

20. National Academies of Sciences, Engineering, and Medicine2016 A framework for educating health professionals to address the social determinants of health. Washington, DC: National Academies Press. Accessed at https://doi.org/10.17226/21923

21. National Academies of Sciences, Engineering, and Medicine 2019 Integrating social care into the delivery of health Care: Moving upstream to improve the nation's health. Washington, DC: National Academies Press. Accessed at https://doi. org/10.17226/25467 